\title{
Çatı Üzeri Doğu-Batı Yönelimli Optimizerli Güneş Enerji Sisteminin Güney Yönelimli Sisteme Göre Üretim Değerlendirmesi ve Ekonomik Analizi
}

\author{
Savaş Alkan ${ }^{1 *}$, Yavuz Ateş ${ }^{2}$ \\ ${ }^{1}$ Sakarya Üniversitesi, Mühendislik Fakültesi, Elektrik Elektronik Mühendisliği Bölümü, Sakarya, Türkiye (ORCID: 0000-0002-8617-3994) \\ ${ }^{2}$ Yıldız Teknik Üniversitesi, Elektrik-Elektronik Fakültesi, Elektrik Mühendisliği Bölümü, İstanbul, Türkiye (ORCID: 0000-0003-0635-9033)
}

(İlk Geliş Tarihi 16 Mart 2020 ve Kabul Tarihi 7 Haziran 2020)

(DOI: 10.31590/ejosat.700182)

ATIF/REFERENCE: Alkan, S. (2019). Çati Üzeri Doğu-Bati Yönelimli Optimizerli Güneş Enerji Santralinin Pilot Uygulamasi Ve Güney Yönelimli Güneş Enerji Santraline Göre Üretim Değerlendirmesi Ve Ekonomik Analizi. Avrupa Bilim ve Teknoloji Dergisi, (19), 375-385.

\section{Öz}

Günümüzde, gelişen teknoloji ve artan nüfusla birlikte enerji talebi de hızla artmakta olup mevcut kaynakların bu talebi çok kısa bir süre daha karşılayabileceği bilimsel bir gerçektir. Ayrıca artan nüfus yoğunluğu ve enerji talebine bağlı olarak karbon salınımlarının artması, hava kirliliği ve iklim değişikliğine neden olmaktadır. Bu tür çevresel etkilerin yaşanmaması ve dünya genelinde sürekli artan enerji talebinin karşılanması adına çevreci ve temiz bir enerji kaynağı olan yenilenebilir enerji kaynaklarının kullanımı neredeyse bir zorunluluk haline gelmiştir. Bu nedenle arazi ve çatı üzeri güneş enerji santrali kurulumları dünya genelinde hızla artmaktadır.

Çatı üzeri güneş enerji santrali kurulumlarında çok önemli iki kıstas bulunmaktadır. Bunlar çatı statiği (yük taşıma kapasitesi) ve çatı izolasyonudur. Bu iki kıstas sağlanmadan çatı üzeri güneş enerji sistemi tesis edilmemelidir. Tesis edilecek güneş enerji santralinden kaynaklı çatıya gelecek ekstra yükler, yapılacak statik hesaplarla analiz edilmeli ve bu hesaplar sonucuna göre kurulum yapılmalıdır. Ayrıca çatı üzeri kurulum yapılmadan önce çatılarda izolasyon sorunu olup olmadığı kontrol edilmelidir. İzolasyon sorunu var ise bu durumun santral kurulumu öncesinde giderilmesi gerekmektedir.

Hidayet Türkoğlu Spor Kompleksinde tesis edilen doğu-batı yönelimli güneş enerji santralinin tasarımı açıklanmıştır. Güneş enerji santrali tasarımı yapılırken kullanılan başlıca simülasyon programlarından bahsedilmiştir. Doğu-batı yönelimli güneş enerji santrali kurularak mevcut alanda güney yönelimli bir santrale göre birim alanda daha fazla güneş enerjisinden faydalanabilineceği simülasyon sonuçlarıyla ortaya konulmuştur. Ayrıca aynı güçlerdeki güney yönelimli ve doğu-batı yönelimli santrallerin simülasyonları yapılarak üretim değerleri karşılaştırılmıştır. Bunula birlikte 2016'da kurulan $169 \mathrm{kWp}$ doğu-batı yönelimli mevcut güneş enerji santralinin veri kayıt ve izleme sisteminden alınan gerçek zamanlı üretim değerleri simülasyon sonuçları ile karşılaştırılmıştır.

Hidayet Türkoğlu Spor Kompleksi'nde tesis edilen $169 \mathrm{kWp}$ kurulu güce sahip çatı üzeri doğu-batı yönelimli optimizerli güneş enerji santralinin 2016 y1lındaki toplam maliyeti $850.00 \mathrm{TL}+\mathrm{KDV}$ ve elektrik birim fiyatı 0,43 TL/kWh'tir. Söz konusu fiyatlar baz alınarak yapılan maliyet analizine göre $169 \mathrm{kWp}$ güneş enerji santralinin yatırım geri dönüşs süresi 15,7 yıl olarak hesaplanmıştır. Santralin kurulumundan bu yana günümüze kadar geçen sürede gelişen teknoloji ile birlikte sistemin yatırımının yarısından fazlasını oluşturan güneş panellerinin maliyeti dünya genelinde $\% 30$ 'a varan oranda düşüş yaşamıştır. Ancak güneş paneli fiyatlarında yaşanan bu düşüş son dönemde ülkemizde artan döviz kurlarından dolayı ciddi oranda hissedilememiştir. Söz konusu sistem günümüzde 750.000 TL+KDV güncel bedel ile kurulabilmektedir. Güncel maliyet ve güncel elektrik birim fiyatı $0,82 \mathrm{TL} / \mathrm{kWh}$ baz alınarak yapılan maliyet analizine göre söz konusu güneş enerji santralinin yatırım geri dönüş süresi 6,7 yıl olarak hesaplanmıştır. Bununla birlikte aynı sistem özelliklerine sahip ve aynı alanda kurulabilecek 110,5 kWp kurulu güçteki güney yönelimli güneş enerji sisteminin, 2020 yılına göre güncel maliyeti $515.000 \mathrm{TL}+\mathrm{KDV}$ 'dir. Güncel sistem maliyeti ve elektrik birim fiyatı baz alınarak yapılan maliyet analizine göre söz konusu güneş enerji santralinin yatırım geri dönüş süresi 6,5 yıl olarak hesaplanmıştır. 2020 yılına göre $169 \mathrm{kWp}$ kurulu güce sahip doğu-batı yönelimli bir güneş enerji sisteminin maliyeti 750.000 TL+KDV olurken 110,5 kWp kurulu güçteki güney yönelimli güneş enerji sisteminin maliyeti $515.000 \mathrm{TL}+\mathrm{KDV}$ olmaktadır. İlk yatırım aşamasında $169 \mathrm{kWp}$ kurulu güce sahip doğu-batı yönelimli güneş enerji sistemi, 110,5 kWp kurulu güçteki güney yönelimli güneş enerji sistemine göre 235.000 TL+KDV daha fazla maliyetli olmaktadır. Doğu-batı yönelimli sistemlerin yatırım geri dönüşs süreleri ekvatora yakın bölgelerde daha kısa olmaktadir

Anahtar Kelimeler: Doğu-batı yönelimli sistem, Optimizer, Fotovoltaik, Enerji üretimi, Ekonomik analiz.

\footnotetext{
* Sorumlu Yazar: Sakarya Üniversitesi, Mühendislik Fakültesi, Elektrik Elektronik Mühendisliği Bölümü, Sakarya, Türkiye, ORCID: 0000-00028617-3994, savasalkan18@ hotmail.com
} 


\title{
Production Evaluation and Economic Analysis of the East-West Oriented Solar Energy System on the Roof according to the South Oriented System
}

\begin{abstract}
Today, with the developing technology and increasing population, the demand for energy is increasing rapidly and it is a scientific fact that the existing resources can meet this demand for a very short time. In addition, increasing carbon emissions due to increasing population density and energy demand cause air pollution and climate change. In order to avoid such environmental impacts and to meet the ever-increasing energy demand worldwide, the use of renewable energy sources, which is an environmentally friendly and clean energy source, has become almost a necessity. For this reason, on-site and rooftop solar power plant installations are increasing rapidly worldwide.

There are two very important criteria in rooftop solar power plant installations. These are roof statics (load bearing capacity) and roof insulation. Without these two criteria, the solar energy system on the roof should not be installed. Extra loads on the roof originating from the solar power plant to be installed should be analyzed with static calculations to be made and installation should be made according to the results of these calculations. Also, before installing on the roof, it should be checked whether there is an insulation problem on the roofs. If there is an isolation problem, this should be resolved before the installation of the exchange.

The design of the east-west oriented solar power plant established in Hidayet Türkoğlu Sports Complex is explained. The main simulation programs used while designing the solar power plant are mentioned. It was revealed by simulation results that an east-west oriented solar power plant was established and that more solar energy could be utilized in the unit area compared to a southern oriented power plant in the current area. In addition, the production values of the south-oriented and east-west oriented power plants with the same powers have been simulated and compared. However, real-time production values obtained from the data recording and monitoring system of the existing $169 \mathrm{kWp}$ east-west oriented solar power plant established in 2016 were compared with the simulation results.

The total cost of the solar power plant with an east-west oriented optimizer on the roof with an installed capacity of $169 \mathrm{kWp}$ installed in Hidayet Türkoğlu Sports Complex in 2016 is $850.00 \mathrm{TL}+\mathrm{VAT}$ and the unit price of electricity is $0.43 \mathrm{TL} / \mathrm{kWh}$. According to the cost analysis based on the said prices, the investment return period of the $169 \mathrm{kWp}$ solar power plant was calculated as 15.7 years. The cost of solar panels, which constitute more than half of the investment of the system with the developing technology since the establishment of the plant, has decreased by up to $30 \%$ worldwide. However, this decrease in solar panel prices has not been felt significantly due to the increasing exchange rates in our country in the recent period. The system in question can now be established with the current price of 750,000 TL + VAT. According to the cost analysis based on the current cost and the current electricity unit price of $0.82 \mathrm{TL} / \mathrm{kWh}$, the investment return period of the said solar power plant was calculated as 6.7 years. However, the current cost of the southern oriented solar energy system with the same system features and an installed power of $110.5 \mathrm{kWp}$ that can be installed in the same area is 515,000 TL + VAT compared to 2020. According to the cost analysis made based on the current system cost and the electricity unit price, the investment return period of the said solar power plant was calculated as 6.5 years. Compared to 2020 , the cost of an east-west oriented solar power system with an installed power of $169 \mathrm{kWp}$ is $750.000 \mathrm{TL}+\mathrm{VAT}$, while the cost of a southern oriented solar power system with an installed power of $110.5 \mathrm{kWp}$ is $515.000 \mathrm{TL}+\mathrm{VAT}$. In the initial investment phase, the east-west oriented solar energy system with $169 \mathrm{kWp}$ installed power is $235.000 \mathrm{TL}+$ VAT more cost compared to the south-oriented solar energy system with $110.5 \mathrm{kWp}$ installed power. Investment return periods of east-west oriented systems are shorter in regions close to equator.
\end{abstract}

Keywords: East-west oriented system, Optimizer, Photovoltaic, Power generation, Economic analysis.

\section{Giriș}

Dünya genelinde kullanılan enerjinin çok büyük bir bölümü, petrol ürünleri (benzin, dizel akaryakıtlar ve propan gibi), doğal gaz, kömür, uranyum (nükleer enerji) gibi yenilenemeyen enerji kaynaklarından oluşmaktadır. Gelişen teknoloji ve artan nüfusla birlikte enerji talebi de hızla artmakta olup bu kaynakların artan talebi çok kısa bir süre daha karşılayabileceği bilimsel bir gerçektir. Ayrıca artan nüfus yoğunluğu ve enerji talebine bağlı olarak karbon salınımlarının artması, hava kirliliği ve iklim değişikliğine neden olmaktadır. Bu çevresel etki devam etmesi durumunda dünya genelinde sıcaklıklar artacak, buzullar eriyecek ve deniz seviyesinde yükselmeler olacaktır. Ayrıca bu çevresel faktörlere ek olarak petrol fiyatlarındaki istikrarsızlık ülkelerin arz güvenliğini ciddi şekilde etkilemektedir. Bu tür çevresel etkilerin yaşanmaması, dünya genelinde sürekli artan enerji talebinin karşılanması ve ülkelerin arz güvenliğinin sağlanması adına çevreci ve temiz enerji kaynağı olan yenilenebilir enerji kaynaklarının kullanımı neredeyse bir zorunluluk haline gelmiştir. Bu konuda devletler tarafından çalışmalar yapılarak kanun, yönetmelik ve mevzuatlar yayınlanmaktadır. Ayrıca kamu ve özel sektör tarafından da yenilenebilir enerji kaynakları için fonlar oluşturulmaktadır. Hatta hükümetler yenilenebilir enerji yatırımcılarına bir takım teşvikler sunmaktadırlar. Söz konusu gelişmeler sayesinde günümüzde yenilenebilir enerji kaynakları, fosil yakıtlara nazaran elektrik üretiminde daha fazla pay almaya başlamıştır [1].

Yenilenebilir enerji kaynaklarının temelini güneş enerjisi oluşturmaktadır. Güneşten gelen 1şınım enerjisi sayesinde fotovoltaik panellerde elektrik üretimi gerçekleştirilmektedir. Fotovoltaik paneller, çevreci ve temiz yenilenebilir enerji üretimine olanak sağladığ 
gibi herhangi bir atı̆̆ı olmadığından ve zararlı bir madde içermediğinden dolayı çevreye duyarlı ekipmanlardır. Ayrıca statik ekipmanlar olduğundan yani yapılarında hareketli veya döner parçalar bulundurmadıklarından, kurulumlarından sonraki işletme ve bakım maliyetleri oldukça düşüktür. Günümüz şartlarında fotovoltaik panellerin maliyetleri biraz yüksektir. Ayrıca fotovoltaik panel verimleri teknolojisi itibariyle düşük olduğundan (ticari olanlar \%15-25 arasında) yatırım geri dönüş süreleri uzun yıllar almaktadır. Ancak gün geçtikçe gelişen teknoloji ile birlikte fotovoltaik panel verimleri artmakta olup maliyetleri ise hızla düşüş göstermektedir. Maliyetleri yüksek, verimleri düşük olmasina rağmen elektrik üretim santrali yaşam boyu maliyet analizlerine bakıldığında en ucuz enerji kaynakalarından biri güneş enerjisi olmaktadır.

Uluslararası Yenilenebilir Enerji Ajansı (IRENA) verilerine göre 2018 yılında dünyada güneş enerjisi toplam kurulu gücü 485 GW seviyesine ulaşmıştır. Gelecek 10 yıl içerisinde, güneş enerjisinin yenilenebilir enerji kapasitesinin büyümesinde liderlik edeceği ve $2.840 \mathrm{GW}$ kurulu güç seviyesine ulaşacağı tahmin edilmektedir. 2018 yılında toplam kurulu güçte ilk 5 sırayı Çin, ABD, Japonya, Almanya ve İtalya almaktadır [2].

2008-2017 yılları arasında Ülkemizde elektrik kullanımı yıllık bazda ortalama \%4,5 artış göstermiş olup sonraki on yıl içerisinde de baz talep tahmin serisine göre yıllık ortalama \%4,5 oranında artı̧ öngörülmektedir [3]. 2017 yılında toplam elektrik tüketimi 294,9 TWh olarak gerçekleşmiştir. 2017 yllında 295 TWh olarak gerçekleşmiş olan elektrik tüketiminin 2027'de 458 TWh seviyesine ulaşması, yani 2017'deki tüketime göre yaklaşık \%55 oranında bir artış olması öngörülmektedir [4].

Türkiye'de yenilenebilir enerji potansiyelinin oldukça yüksek olmasına karşın, 2017 yılındaki elektrik üretiminin \%71,4'ü fosil kaynaklardan elde edilmiştir. Bu üretimi gerçekleştirmek yüksek seviyede enerji kaynağı dışarıdan ithal edilmekte ve bu durum enerji arz güvenliği açısından önemli bir sorun teşkil etmektedir. 2016 yılında üretilen elektrik enerjisinde ülkemizin dışa bağımlılık oranı yüzde 50,7 olarak gerçekleşmiştir. Kurulu güçte ise dışa bağımlılık oranı 2016 y1lında \%43,4, 2017 yılıda ise \%43,2 olarak gerçekleşmiş̧ir. Enerjide dışa bağımlılı̆̆ 1 yüksek olan ülkemizde son zamanlarda özellikle Ortadoğu'da yaşanan siyasi krizlerin artmasıyla ve enerji maliyetlerinin dünya genelinde yükselmesiyle, enerji konusu bir kat daha önem arz etmektedir. Ülkemiz, tükettiği birincil enerji kaynakları petrol ve doğal gazın büyük çoğunluğunu ithalat etmektedir. Gerek birincil enerji kaynaklarının kısıtlı ömrü gerekse de enerjide bağımlı olduğumuz ülkelerdeki siyasal belirsizlikler nedeniyle kullandığımız birincil enerji türlerini çeşitlendirmeye; özellikle Yenilenebilir Enerji’ye yönelmeye gereksinim duyulmaktadır [5].

Ülkemizde lisanssız elektrik üretim yönetmeliğinin yayınlanması ile birlikte bir ivme kazanan yenilenebilir enerji kaynakları kullanımı son 5 yılda özellikle güneş enerjisinde ciddi bir oranda artış göstermiştir. Ülkemizde güneş enerjisi yatırımları 2014 yılında başlamış olup yıl içerisinde $40 \mathrm{MW}$ kurulum yapılmıştır. Güneş enerjisi yatırımları son yıllarda çok hızlı bir yükseliş göstermiştir. 2015 yılında 249 MW'a, 2016 yılında 833 MW'a, 2017 yılında 3.421 MW'a, 2018 yılında 5.063 MW'a, 2019 yılı sonu itibari ile ise 5.595 MW'a ulaşmıştır [6].

Güneş enerjisinden yararlanma adına ülkemizde birçok çalışma yapılmaktadır. Enerji ve Tabii Kaynaklar Bakanlığı tarafından hazırlanan Güneş Enerjisi Potansiyeli Atlası'na (GEPA) göre, ülkemizin yıllık toplam güneşlenme süresi 2.737 saat (günlük 7,5 saat), ülkemize ulaşan yıllık toplam güneş enerjisinin ise $1.527 \mathrm{kWh} / \mathrm{m}^{2}$ yıl olduğu tespit edilmiştir [7]. Türkiye, güneş ışınımı açısından dünya ortalamasının üzerinde ışınım almaktadır. Ayrıca güneşlenme süresi uzun olduğundan elektrik üretimi açısından oldukça elverişli bir konumdadır.

Son yıllarda güneş enerjisinde farkındalığın artması ve bir takım teşviklerin gelmesiyle birlikte fotovoltaik çatı uygulamaları hız kazanmıştır. Ancak özellikle çatılarda bulunan baca, anten, baz istasyonu, klima dış ünitesi, aydınlık vb. gibi etkenlerden dolayı alan kayıpları yaşanmaktadır. Yaşanan alan kayıplarından dolayı çatı alanın müsaade ettiği ölçüde belirli bir kapasitede güneş enerji sistemi kurulabilmektedir. Hâlihazırda sınırlı olan ve yukarıda bahsedilen etkenlerden dolayı daha da sınırlanan çatı alanlarında güneş enerjisinden daha fazla yararlanabilmek adına doğu-batı yönelimli kurulumlar popüler çalışma alanı haline gelmiştir.

Sabit güneş enerji sistemlerinde en fazla verim güney yönelimde kurulum ile elde edilir. Ancak güney yönelimde kurulan çatı üzeri güneş enerji sistemlerinde güneşin ilk ve son saatlerinde üretim az olmaktadır. Ayrıca çatı alanı sınırlı olan yerlerde, aynı çatı alanı için güney yönelime göre doğu-batı yönelimde daha fazla kurulu güçte güneş enerji sistemi tesis edilebilmektedir. Sınırlı çatı alanlarında santral kurulu gücü ile güneşin ilk ve son saatlerindeki üretimi artırmak adına doğu-batı yönelimli sistemler son yıllarda hızla artış göstermektedir.

Apama Sankar ve Anish Kalathil doğu-batı ve güney yönelimli fotovoltaik sistemlerin performansını, mevsim, güneş açısı, güneşlenme süresi, hava durumu gibi farklı değişkenlerin etkisi altında incelemişlerdir. Güney yarım kürede bulunan Hindistan HQ kampüsünde çatı üzerine kurulan doğu-batı ve güney yönelimli fotovoltaik sistemlerin çıktılarını analiz ederek, aynı çatı alanı için $14,58 \mathrm{kWp}$ kurulu güce sahip doğu-batı yönelimli ve $10,08 \mathrm{kWp}$ güney yönelimli fotovoltaik sistemlerin gerçek zamanlı verilerini karşılaştırmışlardır. Hindistan'da kurulan sistemin güney yarım kürede ve ekvatora yakın bulunması sayesinde güneşlenme süresinin yüksek olacağı ve panellerin maksimum düzeyde ışınıma maruz kalacağını öngörmüşlerdir. Her 15 dakikada bir alınan gerçek zamanlı verileri, Mart, Haziran, Eylül ve Aralık ayları için karşılaştırmışlardır. Bu aylardaki verilerin incelenmesinin nedeni güneşin mevsimsel hareketindeki dünyanın enlemlerine yani ekinokslara, yaz gündönümüne ve kış gündönümüne göre kritik dönemleri temsil etmesi olarak açıklamışlarıdır. Doğu-batı yönelimli sistemin güney yönelimli sisteme göre söz konusu aylarda yaklaşık \%6 oranında daha fazla üretim yaptığını tespit etmişlerdir. Ayrıca doğu-batı yönelimli sistemde enerji üretiminin sabah ve öğleden sonraki saatlerde daha fazla olduğunu, güney yönelimli sistemde ise gün ortasında daha fazla olduğunu ortaya çıkarmışlardır. Bu sayede doğu-batı sistemlerin, yük profili ile gün içerisinde daha uzun süreli ve daha iyi eşleştiğini ortaya koymuşlardır. Her iki sistemi aynı alan için değerlendirdiklerinde doğu-batı yönelimli sistemin, güney yönelimli sisteme göre $\% 33$ daha fazla kurulu güçte tesis edilebildiğini ortaya koymuşlardır [8]. 
Bu çalışmada doğu-batı yönelimli güneş enerji sistemlerinin, güneşlenme süresinin yüksek olduğu ekvatora yakın olan bölgelerde kurulmasının güney yönelimli sistemlere göre daha avantajlı olacağı ortaya konulmaktadır. Ayrıca Bölüm 2'de doğu-batı yönelimli güneş enerji santralinin tasarımı ayrıntılı olarak açıklanmıştır. Doğu-batı yönelimli ile güney yönelimli güneş enerji santrallerinin aynı güç ve aynı alan için simülasyonları yapılarak analiz edilmiş ve her iki sistem için maliyet analizleri yapılarak Bölüm 3'de verilmiştir. Son olarak, elde edilen en önemli sonuçlar Bölüm 4'de verilmiştir.

\section{Materyal ve Metot}

\subsection{Sistem Tasarımı}

İstanbul Büyükşehir Belediyesi'ne ait Hidayet Türkoğlu Spor Kompleksi'nde elektrik enerjisi ihtiyacının bir kısmının karşılanması amacıyla kurulan $169 \mathrm{kWp}$ kurulu güce sahip şebeke bağlantılı, doğu-batı yönelimli çatı üzeri güneş enerji santralinin tasarımında; $260 \mathrm{Wp}$ güce sahip 650 adet polikristal güneş paneli, $8 \mathrm{~kW}$ güce sahip 25 adet 3 fazlı solar inverter, panel bazlı izleme ve panel bazlı maksimum güç takibi olanağı sağlayan 650 adet optimizer, AC güç panosu, güneş enerji sistemine uygun dayanım ve özelliklerde doğu-batı yönelimli taşıcı sistem ve bilgi ekranı (kiosk) kullanılmıştır.

Çatı üzeri güneş enerji santrali kurulumlarında çok önemli iki kıstas bulunmaktadır. Bunlar çatı statiği (yük taşıma kapasitesi) ve çatı izolasyonudur. Bu iki kıstas sağlanmadan çatı üzeri güneş enerji sistemi tesis edilmemelidir. Tesis edilecek güneş enerji santralinden kaynaklı çatıya gelecek ekstra yükler, yapılacak statik hesaplarla analiz edilmeli ve bu hesaplar sonucuna göre kurulum yapılmalıdır. Ayrıca çatı üzeri kurulum yapılmadan önce çatılarda izolasyon sorunu olup olmadığı kontrol edilmelidir. İzolasyon sorunu var ise bu durumun santral kurulumu öncesinde giderilmesi gerekmektedir. Hidayet Türkoğlu Spor Kompleksi’nde kurulum yapılmadan önce statik hesaplar yapılmış uygun görülmüştür. Ayrıca güneş enerji sistemi kurulmadan önce çatı izolasyonu yenilenmiştir.

Panel taşıyıcı sistemin tasarımı doğu-batı yönelimli olacak şekilde paslanmalara karşı dayanımı yüksek ve uzun ömürlü olan alüminyum malzemden yapılmıştır. Hidayet Türkoğlu Spor Kompleksi konumu için yapılan simülasyonlarla, doğu-batı yönelimli konstrüksiyonun eğim açısı $11^{\circ}$ olacak şekilde belirlenmiştir. Şekil 2.1.'de Panel taşıyıcı konstrüksiyon modeline ait görsel paylaşılmıştır. Tasarımı yapılan konstrüksiyon zemine sabitlenmeden ağırlık sistemi yöntemi ile monte edilmiş̧ir. Ağırlık sisteminde balast betonu olarak dikdörtgen parke taşları kullanılmıştır. Balast beton olarak kullanılan parke taşlarının yerleri ve adetleri statik hesaba göre belirlenmiş ve uygun sayıda konulmuştur. Kullanılan parke taşının hacmi $1,16 \mathrm{dm}^{3}(100 \mathrm{~mm}$ x 200mm x $80 \mathrm{~mm})$ ağırlığı ise $3,5 \mathrm{~kg}$ 'dir.

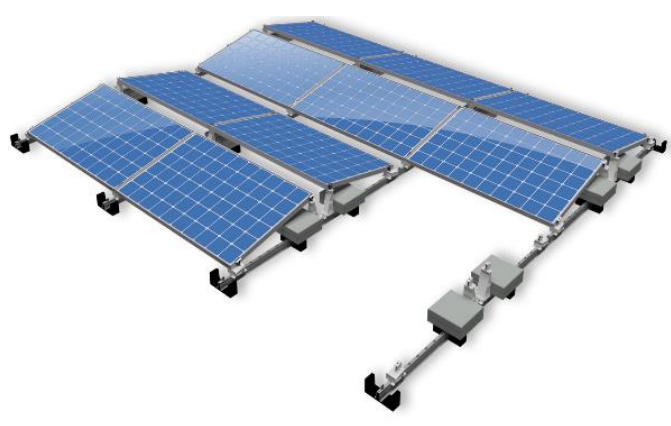

Şekil 2.1. Doğu-Batı yönelimli taşıyıcı sistem[9]

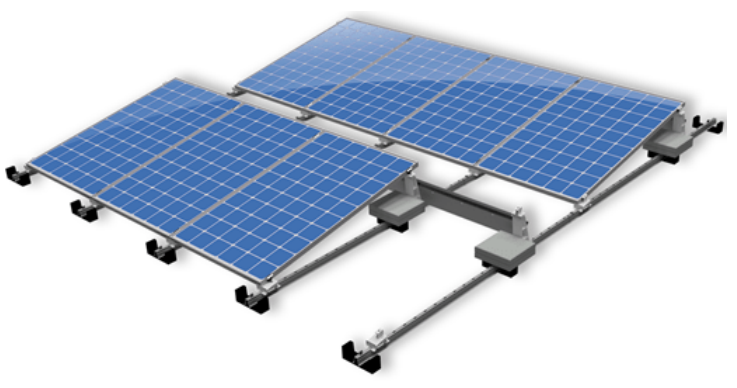

Şekil 2.2. Güney yönelimli taşıyıcl sistem [10]

Şekil 2.1.'deki doğu-batı kurulumda eğim açısı düşük, $11^{\circ}$ olduğundan paneller arası gölgelenme mesafesi bırakılmasına gerek yoktur. Şekil 2.2.'de görüldüğü üzere güney yönelimli sistemde ön sıradaki panelin arka sıradaki panele gölge yapmaması için eğim açıssında göre değişen uzunlukta bir mesafe bırakılmalıdır. Özellikle çatılarda bulunan baca, anten, baz istasyonu, klima dış ünitesi, parapet, aydınlık vb. gibi etkenlerden dolayı alan kayıplarının yanı sıra birde gölgelenme mesafesi bırakıldığında çok ciddi alan kayıpları yaşanmaktadır. Yaşanan alan kayıplarından dolayı çatı alanın müsaade ettiği ölçüde belirli bir kapasitede güneş enerji sistemi kurulabilmektedir. Hâlihazırda sınırlı olan ve yukarıda bahsedilen etkenlerden dolayı daha da sınırlanan çatı alanlarında güneş enerjisinden daha fazla yararlanabilmek adına doğu-batı yönelimli sistemler kurulmaktadır.

Doğu batı sistem tasarımı ile güneş doğarken ve batarken güneş ışınımlarından maksimum düzeyde yararlanılmaktadır. Güney yönelimli uygulamalarda güneş ışınları sadece belirli bir zaman diliminde panellere dik olarak düşmektedir. Doğu-batı sistemde ise güneş güney yöndeyken daha az üretim olmasına karşın güneş doğarken ve batarken ki zaman diliminde daha fazla enerji üretimi yapılabilmektedir. Aynı zamanda doğu-batı sistem ile aynı alanda daha fazla güneş enerji sistemi kurulabilmektedir. Örneğin 1.500 $\mathrm{m}^{2}$, çatı alanı bulunan Hidayet Türkoğlu Spor Kompleksi'nde $11^{\circ}$ doğu batı yönelimli sistem kurulduğunda $169 \mathrm{kWp}, 30^{\circ}$ güney yönelimli bir sistem kuruluduğunda ise $110,5 \mathrm{kWp}$ kurulu gücünde kurulum yapılabilecekti.

Ayrıca sistem tasarımında klasik güneş enerji sistemlerinin dışında sistem verimin arttırlıması için optimzer kullanılmıştır. Optimizer DC/DC dönüştürücü elektronik bir devredir. Optimizer sistemde, gölgelenme kaynaklı etkilerin minimize edilmesi, paneller arası uyumsuzluk (mismatch) farkından kaynaklı etkinin ortadan kaldırılması, farklı eğimde, yönelimde ve güçte panel 
kullanılmasına olanak sağlanması, yüksek DC voltajdan koruma sağlanması, panel bazlı izleme yapılabilmesi ve buna bağlı işlteme ve bakım maliyetlerinin düşürülmesi gibi faydalar sağlamaktadır. Ancak elektronik bir devre olduğundan çok düşükte olsa sistemde bir enerji kaybına neden olmakta $(\% 0,5)$ ve ayrıca güneş enerji sistemlerinde kullanılan ekstra bir cihaz olduğundan sistem maliyetinin yaklaşık \% 7'sini oluşturarak sistemin ilk yatırım maliyetini yükseltmektedir [11].

\section{Araştırma Sonuçları ve Tartışma}

\subsection{Simülasyon Sonuçları}

Piyasada birçok fotovoltaik simülasyon programı bulunmaktadır. Bunlardan başlıcaları; PVSol, PVSyst, PVGIS, PVWats, Sunny Design, Archelios, HelioScpoe vb. programlardır. Ayrıca inverter üreticilerine ait birçok program bulunmaktadır. Güneş enerji santrali kurulumu öncesi doğru bir tasarım yapılabilmesi için simülasyon yapılmalıdır. Bu tür programlar santralin kurulu gücünün ve üretim tahminlerinin tespiti ile ekonomik analizinin yapılabilmesine olanak sağlamaktadır [12].

Güneş enerji santralinde kullanılacak güneş panelleri, gerilim üreteci olarak farklı sayılarda dizi oluşturacak şekilde seri bağlanır. Güneş panellerinin seri ve dizi sayısı tespit edilirken inverterin çalışma aralıkları ile uyumlu olacak şekilde belirlenmesi gerekmektedir. Her solar inverterin DC giriş tarafında farklı MPP giriş aralığı vardır. Ayrıca her solar inverter giriş akımı ve gerilimi sınırlandırılmıştır. Olası tasarımlar için güneş panellerinin dizilimi ve eğimi simülasyon programları ile tahmin edilerek değerlendirilebilir. Bu programlarla tasarım desteğinin yanında gölgelenme analizi, verim analizi, enerji üretim ve emisyon tasarruf miktarları, tesis devre şemalarının çizimi ve ekonomik analiz yapılarak bir rapor halinde çıktı alınabilmektedir. Söz konusu simülasyon programları içerisinde PVSol kullanılarak $169 \mathrm{kWp}$ doğu batı, $169 \mathrm{kWp}$ güney ve 110,5 kWp güney yönelimli sistemlerin simülasyonları yapılarak karşılaştırılmıştır.

\subsection{1. $169 \mathrm{kWp} 11^{\circ}$ Doğu-Batı Yönelimli Sistem ile $169 \mathrm{kWp} 30^{\circ}$ Güney Yönelimli Sistemin Karşılaştırması}

Simülasyon yapılırken aynı güçte farklı yönelimdeki iki sistem arasındaki üretim ve verim farkının ortaya konulması amaçlanmıştır. Tablo 3.1.'de $169 \mathrm{kWp}$ gücündeki $11^{\circ}$ doğu-batı ve $30^{\circ}$ güney yönelimli sistemlerin aylara göre enerji üretim değerleri karşılaştırmalı olarak verilmiştir.

Tablo 3.1. $169 \mathrm{kWp}$ gücündeki $11^{\circ}$ doğu-batı ve $30^{\circ}$ güney yönelimli sistemlerin aylara göre enerji üretim karşılaştırmaları

\begin{tabular}{|c|c|c|}
\hline \multicolumn{3}{|c|}{ Aylara Göre Enerji Üretim Karşılaştırması } \\
\hline Ay & kWh (Doğu-Batı) & kWh (Güney) \\
\hline Ocak & 6,74 & 10,04 \\
\hline Şubat & 8,07 & 10,17 \\
\hline Mart & 14,06 & 15,92 \\
\hline Nisan & 21,08 & 22,2 \\
\hline Mayıs & 24,02 & 23,17 \\
\hline Haziran & 26,24 & 24,45 \\
\hline Temmuz & 26,59 & 25,1 \\
\hline Ağustos & 22,6 & 22,9 \\
\hline Eylül & 16,73 & 18,67 \\
\hline Ekim & 11,4 & 14,58 \\
\hline Kasım & 8,49 & 12,79 \\
\hline Aralık & 6,86 & 11,2 \\
\hline Toplam & 192,88 & 211,25 \\
\hline
\end{tabular}




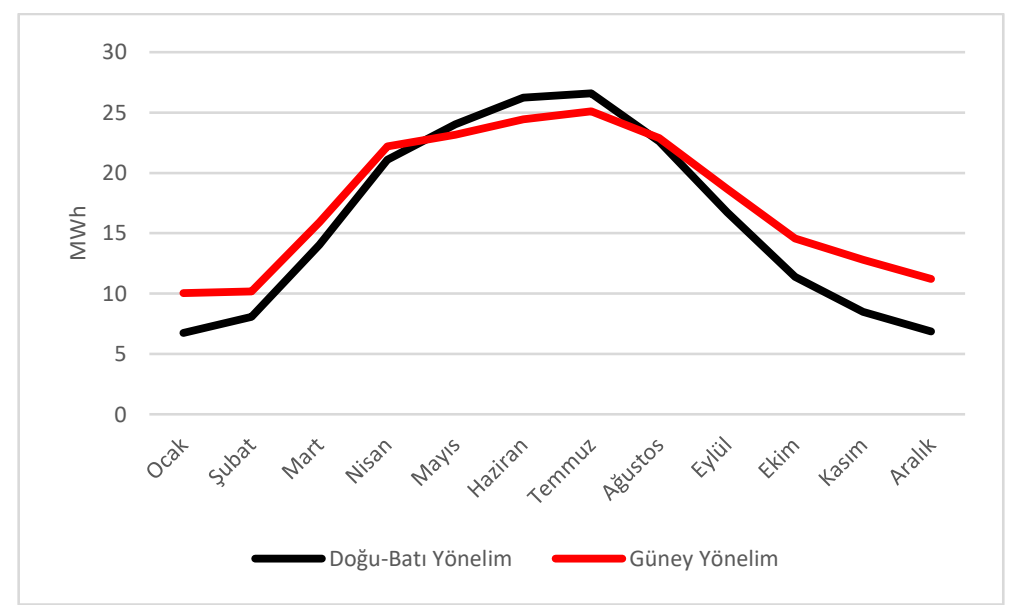

Şekil 3.1. $169 \mathrm{kWp}$ gücündeki $11^{\circ}$ doğu-batı ve $30^{\circ}$ güney yönelimli sistemlerin aylara göre enerji üretim eğrileri

Simülasyon programının sonuçlarına göre hem doğu-batı yönelimli hem de güney yönelimli güneş enerji sistemi için temmuz ayı, üretimin en yüksek olduğu aydır. Şekil 3.1.'deki grafikten de görüleceği üzere doğu-batı yönelimli sistemde, güneşlenme süresinin yüksek olduğu mayıs, haziran ve temmuz aylarında elektrik üretimi daha fazla olmaktadır. Diğer aylarda ise güney yönelimli sistemde elektrik üretimi daha fazla olmaktadır. Bu durum söz konusu aylarda güneşlenme süresinin yüksek olması olarak açıklanabilir.

Simüle edilen $169 \mathrm{kWp}$ kurulu güçte farklı yönelimlerdeki sistemlerin, enerji üretim değerleri karşılaştırıldığında; güney yönelimli güneş enerji sisteminin, doğu-batı yönelimli güneş enerji sistemine göre yıllık $(211.250-192.829) / 192.829=\% 9,55$ daha fazla üretim yaptığı görülmektedir. Ancak mevcut çatı alanına kurulan doğu-batı yönelimli güneş enerji sistemi yerine, aynı çatı alanına $\left(1500 \mathrm{~m}^{2}\right) 30^{\circ}$ güney yönelimli bir güneş enerji sistemi kurulsaydı, maksimum $110,5 \mathrm{kWp}$ kurulu güçte bir sistem kurulumu gerçekleştirilebilecekti.

\subsection{2. $169 \mathrm{kWp} 11^{\circ}$ Doğu-Batı Yönelimli Sistem ile 110,5 $\mathrm{kWp} 30^{\circ}$ Güney Yönelimli Sistemin Karşılaştırması}

Simülasyon ile aynı çatı alanındaki farklı güç ve yönelimlerdeki sistemler arasındaki üretim farkının ortaya konulması amaçlanmıştır. Tablo 3.2.'de $169 \mathrm{kWp}$ gücündeki $11^{\circ}$ doğu-batı ve $110,5 \mathrm{kWp}$ gücünde $30^{\circ}$ güney yönelimli sistemlerin aylara göre enerji üretim değerleri karşılaş̧ırmalı olarak verilmiştir.

Tablo 3.2. $169 \mathrm{kWp}$ gücündeki $11^{\circ}$ doğu-batı ve $110,5 \mathrm{kWp}$ gücünde $30^{\circ}$ güney yönelimli sistemlerin aylara göre enerji üretim karşılaştırmaları

\begin{tabular}{|c|c|c|}
\hline \multicolumn{3}{|c|}{ Aylara Göre Enerji Üretim Karşılaştırması } \\
\hline Ay & kWh (Doğu-Batı) & kWh (Güney) \\
\hline Ocak & 6,74 & 5,81 \\
\hline Şubat & 8,07 & 7,16 \\
\hline Mart & 14,06 & 10,83 \\
\hline Nisan & 21,08 & 14,73 \\
\hline Mayıs & 24,02 & 15,61 \\
\hline Haziran & 26,24 & 16,52 \\
\hline Temmuz & 26,59 & 17,02 \\
\hline Ağustos & 22,6 & 15,42 \\
\hline Eylül & 16,73 & 12,47 \\
\hline Ekim & 11,4 & 9,30 \\
\hline Kasım & 8,49 & 7,45 \\
\hline Aralık & 6,86 & 5,33 \\
\hline Toplam & 192,88 & 137,63 \\
\hline
\end{tabular}




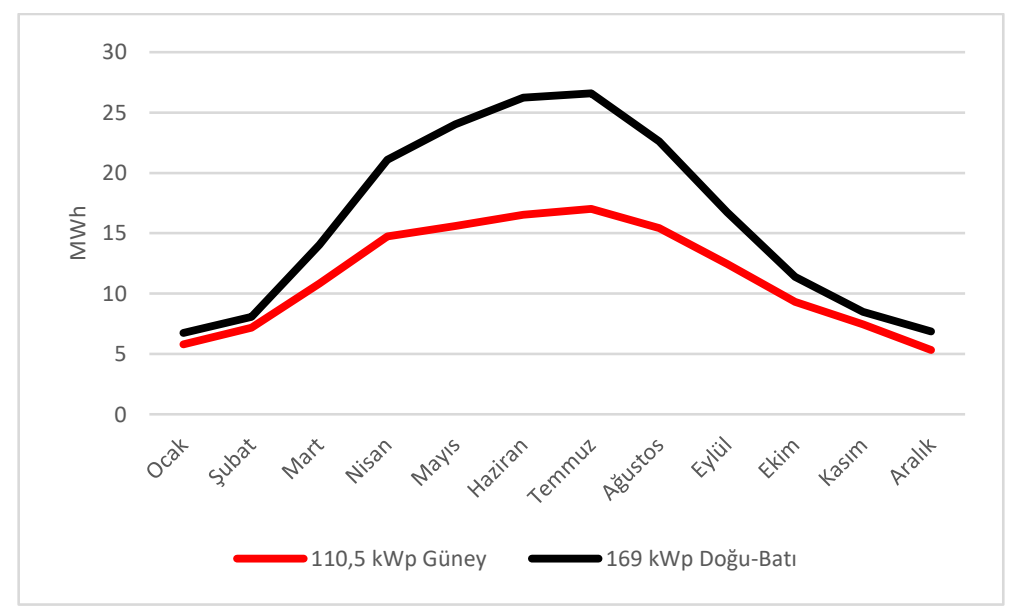

Şekil $3.2169 \mathrm{kWp} 11^{\circ}$ doğu-batı yönelimli güneş enerji sistemi ile 110,5 kWp $30^{\circ}$ güney yönelimli güneş enerji sisteminin aylara göre enerji üretim ĕ̆rileri

Grafiktede görüldüğü üzere güç farkından dolayı doğu-batı yönelimli güneş enerji sistemi, güney yönelimli sisteme göre yıl boyunca daha fazla enerji üretmektedir. Aynı çatı alanı için güney yönelimli sistem yerine doğu-batı yönelimli sistem kurulduğunda yaklaşık \%35 daha fazla kurulu güçte kurulum yapılabilmektedir. Simülasyonu yapılan $169 \mathrm{kWp}$ doğu batı yönelimli güneş enerji sisteminden yıllık $192.829 \mathrm{kWh}$ üretim yapılırken aynı çatı alanına tesis edilecek 110,5 kWp güney yönelimli sistem ile $137.633 \mathrm{kWh}$ üretim yapılabilmektedir.

Simüle edilen farklı güç ve yönelimdeki sistemlerin, enerji üretim değerleri kıyaslandığında; doğu-batı yönelimli güneş enerji sisteminin, güney yönelimli güneş enerji sistemine göre yıllık (192.829 - 137.633) / 137.633= \% 40 daha fazla üretim yaptığ 1 görülmektedir. Aynı çatı alanına güney yönelimli kurulum yerine doğu-batı yönelimli güneş enerji sistemi kurulumu yaparak güneş enerjisinden $\% 40$ daha fazla yararlanılabilmektedir.

\subsection{Reel Üretim İle Simülasyon Sonuçlarının Karşılaştırması}

İstanbul Büyükşehir Belediyesi'ne ait Hidayet Türkoğlu Spor Kompleksi'nde 2016 yılında tesis edilen 169 kWp gücündeki çatı üzeri doğu-batı yönelimli güneş enerji santralinin gerçek zamanlı enerji üretimi verileri yıllık bazda izlenmiştir. Veri kayıt ve izleme sisteminden alınan gerçek zamanlı üretim verilerine göre söz konusu sistemde yılda 202,85 MWh elektrik üretildiği görülmüş ve PVSol simülasyonundan elde edilen sonuçlar ile karşılaştırılarak Tablo 3.3.’te verilmiştir [13].

Tablo 3.3. 169 kWp doğu-batı yönelimli güneş enerji santralinin aylara göre PVSol ve gerçek zamanlı enerji üretim verileri

\begin{tabular}{|c|c|c|}
\hline TARİH & PVSol (MWh) & Reel Üretim(MWh) \\
\hline Ocak & 6,74 & 5,75 \\
\hline Şubat & 8,07 & 6,47 \\
\hline Mart & 14,06 & 16,85 \\
\hline Nisan & 21,08 & 22,52 \\
\hline Mayıs & 24,02 & 25,25 \\
\hline Haziran & 26,24 & 26,91 \\
\hline Temmuz & 26,59 & 27,78 \\
\hline Ağustos & 22,6 & 22,28 \\
\hline Eylül & 16,73 & 19,85 \\
\hline Ekim & 11,4 & 14,57 \\
\hline Kasim & 8,49 & 8,47 \\
\hline Aralı & 6,86 & 6,15 \\
\hline Toplam & 192,88 & 202,85 \\
\hline & &
\end{tabular}




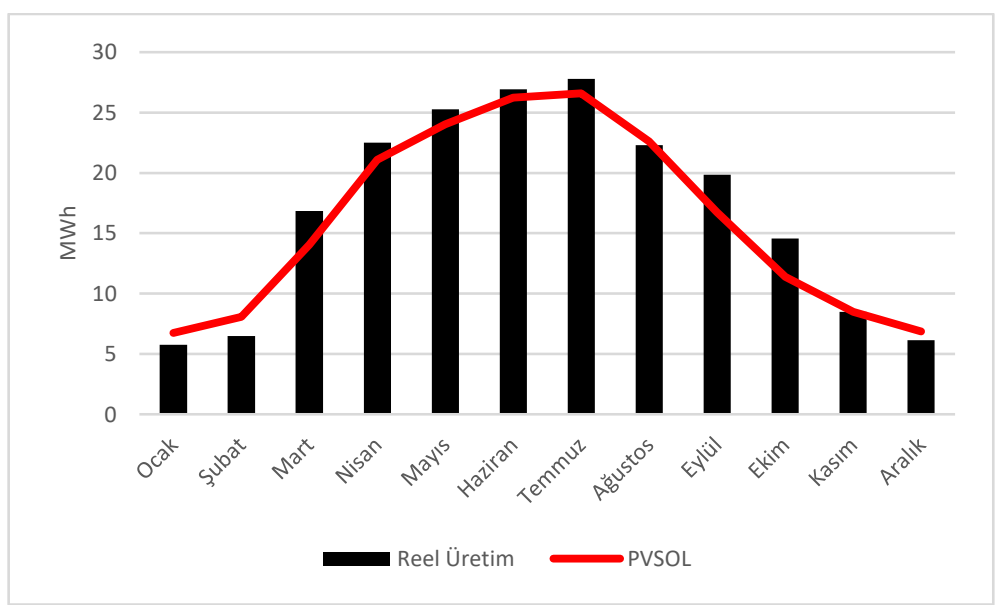

Şekil 3.3. 169 kWp doğu-batı yönelimli güneş enerji santralinin aylara göre PVSol ve gerçek zamanlı enerji üretim eğrisi

Gerçek zamanlı enerji üretim eğrisinin karakteristiği PVSol programı ile yapılan simülasyon sonucu ortaya çıkan üretim karakteristiği ile benzerlik göstermektedir. Similasyon ve gerçek zamanlı üretim verilerine göre en fazla üretim Temmuz ayında gerçekleşmiştir. Gerçek zamanlı enerji üretim değerleri, PVSol programı ile yapılan simülasyon sonuçlarına göre \%5,16 daha fazladır. Yapılan simülasyon ortaya çıkarmıştır ki uygulaması yapılan sistemine ait gerçek veriler; simülasyon verilerine göre daha yüksek üretim olduğunu göstermektedir.

\subsection{Maliyet ve Amortisman Analizi}

Hidayet Türkoğlu Spor Kompleksi'nde tesis edilen 169 kWp kurulu güce sahip çatı üzeri doğu-batı yönelimli optimizerli güneş enerji sistemi için kullanılan 650 adet $260 \mathrm{Wp}$ fotovoltaik güneş panelinin, 650 adet $300 \mathrm{~W}$ optimizerin, 25 adet $8 \mathrm{~kW}$ inverterin, konstrüksiyon ve balast betonların, meteoroloji istasyonunun, fotovoltaik kabloların, pano ve şalt ekipmanların, uzaktan izleme sisteminin, topraklama ve yıldırım tesisatının, nakliye, projelendirme ve onay işlerinin 2016 yllındaki toplam maliyeti 850.00 TL+KDV'dir. Bu toplamı oluşturan kalemler Tablo 3.4.'te verilmiştir.

Tablo 3.4. 169 kWp kurulu güce sahip doğu-bat yönelimli optimizerli güneş enerji sisteminin 2016 yılı maliyeti

\begin{tabular}{|l|c|c|c|c|}
\hline \multicolumn{1}{|c|}{ Malzeme/Hizmet Adı } & Birim & Miktar & Birim Fiyat (TL) & Toplam Fiyat (TL) \\
\hline Güneş paneli & Adet & 650 & 678 & 440.700 \\
\hline İnverter & Adet & 25 & 3.400 & 85.000 \\
\hline Optimizer & Adet & 650 & 102 & 66.300 \\
\hline Taşıııcı konstrüksiyon ve balast betonu & Takım & 1 & 170.000 & 170.000 \\
\hline Kablo ve konnektör & Takım & 1 & 32.300 & 32.300 \\
\hline Pano ve şalt ekipmanları & Adet & 1 & 22.000 & 22.000 \\
\hline Meteoroloji istasyonu & Adet & 1 & 9.000 & 9.000 \\
\hline Uzaktan izleme & Adet & 1 & 200 & 200 \\
\hline Topraklama ve yıldırım & Takım & 1 & 4.500 & 4.500 \\
\hline Proje ve onay işleri & Takım & 1 & 12.000 & 12.000 \\
\hline Nakliye & Adet & 1 & 8.000 & 8.000 \\
\hline & \multicolumn{5}{|l}{ Toplam (TL) } & $\mathbf{8 5 0 . 0 0 0}$ \\
\hline
\end{tabular}

2016 yılı santral kurulum maliyeti $850.000 \mathrm{TL}+\mathrm{KDV}$ ve elektrik birim fiyatı $0,43 \mathrm{TL} / \mathrm{kWh}$ baz alınarak yapılan maliyet analizine göre $169 \mathrm{kWp}$ güneş enerji santralinin yatırım geri dönüş süresi 15,7 yıl olarak hesaplanmıştır. 2016 yılından günümüze kadar gelişen teknoloji ile birlikte sistem yatırımının yarısından fazlasını oluşturan güneş panellerinin maliyeti dünya genelinde \%30'a varan oranda düşüş yaşamıştır. Ancak güneş paneli fiyatlarında yaşanan bu düşüş son dönemde ülkemizde artan döviz kurlarından dolayı ciddi oranda hissedilememiştir. Söz konusu sistem günümüzde 750.000 TL+KDV güncel bedel ile kurulabilmektedir [14]. Sistemin yatırım geri dönüş süresi hesabı, güneş paneli enerji üretim projeksiyonu dikkate alınarak aşağıdaki denklem ile hesaplanmıştır.

$$
\tau=-C_{y a t}+\sum_{t=1}^{T} C_{T}
$$

2016 yılında Hidayet Türkoğlu Spor Kompleksi’nde yapımına başlanan çatı üzeri doğu-batı yönelimli 169 kWp kurulu güce sahip güneş enerji sisteminin, 2020 yılına göre güncel maliyeti 750.000 TL+KDV'dir. Güncel maliyet ve güncel elektrik birim fiyatı 0,82 
TL/kWh baz alınarak yapılan maliyet analizine göre söz konusu güneş enerji santralinin yatırım geri dönüşsüresi 6,7 y1l olarak hesaplanmıştır.

Bununla birlikte aynı sistem özelliklerine sahip 110,5 kWp kurulu güçteki güney yönelimli güneş enerji sisteminin, 2020 yılına göre maliyeti $515.000 \mathrm{TL}+\mathrm{KDV}$ 'dir. Sistem maliyeti ve güncel elektrik birim fiyatı $0,82 \mathrm{TL} / \mathrm{kWh}$ baz alınarak yapılan maliyet analizine göre söz konusu güneş enerji santralinin yatırım geri dönüş süresi 6,5 yıl olarak hesaplanmıştır.

2020 yılına göre $169 \mathrm{kWp}$ kurulu güce sahip doğu-batı yönelimli bir güneş enerji sisteminin maliyeti $750.000 \mathrm{TL}+\mathrm{KDV}$ olurken $110,5 \mathrm{kWp}$ kurulu güçteki güney yönelimli güneş enerji sisteminin maliyeti $515.000 \mathrm{TL}+\mathrm{KDV}$ olmaktadır. İlk yatırım aşamasında 169 $\mathrm{kWp}$ kurulu güce sahip doğu-batı yönelimli bir güneş enerji sistemi, 110,5 kWp kurulu güçteki güney yönelimli bir güneş enerji sistemine göre $(750.000-515.000)=235.000 \mathrm{TL}+\mathrm{KDV}$ daha fazla maliyetli olmaktadır. Özetle ilk yatırım maliyeti olarak iki sistem karşılaştırıldığında $169 \mathrm{kWp}$ kurulu güce sahip doğu-batı yönelimli güneş enerji sistemi, aynı sistem bileşenlerine sahip 110,5 kWp kurulu güçteki güney yönelimli bir güneş enerji sistemine göre $\% 45$ daha yüksek maliyetli olmaktadır.

Söz konusu maliyetler ve elektrik birim fiyatı baz alınarak yapılan maliyet analizine göre $169 \mathrm{kWp}$ kurulu güce sahip doğu-batı yönelimli bir güneş enerji sisteminin yatırım geri dönüş süresi 6,7 yll olurken $110,5 \mathrm{kWp}$ kurulu güçteki güney yönelimli bir güneş enerji sisteminin yatırım geri dönüş süresi 6,5 yıl olmaktadır. Yatırım geri dönüşs süresi olarak söz konusu iki sistem karşılaştırıldığında $110,5 \mathrm{kWp}$ kurulu güçteki güney yönelimli güneş enerji sisteminin yatırım geri dönüş 0,2 yıl daha erken olmaktadır. Ancak her iki sistem üretim değerleri açısından karşılaştırıldığında Tablo 3.5.'te verilen gerçek zamanlı üretim verisine göre $169 \mathrm{kWp}$ kurulu güce sahip doğu-batı yönelimli bir güneş enerji sisteminden yılda $202.510 \mathrm{kWh}$ elektrik üretilirken, PVSol ile yapılan simülasyon verisine göre $110,5 \mathrm{kWp}$ kurulu güçteki güney yönelimli güneş enerji sisteminden $137.633 \mathrm{kWh}$ elektrik üretilmektedir. Ayrıca bu üretimler karşılaştırıldığında $169 \mathrm{kWp}$ kurulu güce sahip doğu-batı yönelimli sistem 110,5 kWp kurulu güçteki güney yönelimli güneş enerji sistemine göre yılda $(202.510-137.633)=65.213 \mathrm{kWh}$ daha fazla elektrik üretmiştir. Bu üretimle $169 \mathrm{kWp}$ kurulu güce sahip doğu-batı yönelimli sistem, $110,5 \mathrm{kWp}$ kurulu güçteki güney yönelimli güneş enerji sistemine yılda \%47 oranında daha fazla üretim yaparak 53.607 TL daha fazla gelir sağlamaktadır. Karşılaştırmalı olarak her iki sisteme ait tesis maliyeti, enerji üretimi, üretim getirisi, engellenen karbon $\left(\mathrm{CO}_{2}\right)$ salınımı, doğaya sağlanan ağaç katkısı, elektrik tüketimi karşılanacak hane sayısı ve yatırım geri dönüş süresi gibi veriler bulunmuş ve sonuçları Tablo 3.5.'te verilmiştir.

Tablo 3.5. Her iki sisteme ait kurulum maliyetleri ve çıktılar

\begin{tabular}{|c|c|c|c|c|c|c|c|}
\hline $\begin{array}{c}\text { Yönelim } \\
\text { Durumu }\end{array}$ & $\begin{array}{c}\text { Tesis } \\
\text { Maliyeti } \\
\text { (TL) }\end{array}$ & $\begin{array}{c}\text { Enerji } \\
\text { Üretimi } \\
\text { (kWh/yıl) }\end{array}$ & $\begin{array}{c}\text { Üretim } \\
\text { Getirisi } \\
\text { (TL/yıl) }\end{array}$ & $\begin{array}{c}\text { Karbon Ayak } \\
\text { İzi (ton/yll) }\end{array}$ & $\begin{array}{c}\text { Ağaç Katkısı } \\
\text { (adet/yıl) }\end{array}$ & $\begin{array}{c}\text { Hane Sayısı } \\
\text { (adet/yıl) }\end{array}$ & $\begin{array}{c}\text { Yatırım Geri } \\
\text { Dönüşü (yıl) }\end{array}$ \\
\hline $\begin{array}{c}\text { 169 kWp Doğu- } \\
\text { Batı Sistem }\end{array}$ & 750.000 & 202.846 & 166.743 & 105,48 & 2.704 & 130 & 6,7 \\
\hline $\begin{array}{c}\text { 110,5 kWp } \\
\text { Güney Sistem }\end{array}$ & 515.000 & 137.633 & 113.136 & 71,57 & 1.835 & 88 & 6,5 \\
\hline $\begin{array}{c}\text { Sistemlerin } \\
\text { Farkları }\end{array}$ & 235.000 & 65.213 & 53.607 & 33,91 & 869 & 42 & 0,2 \\
\hline
\end{tabular}

\section{Sonuç}

Doğu-batı yönelimli güneş enerji sisteminin en önemli özelliği, güney yönelimli sisteme göre birim alanda daha fazla kurulu güç tesis edilmesine olanak sağlamasıdır. Sistemin bu yeteneği sayesinde, yüksek güçlerde kurulum yapılarak, güneş enerjisinden maksimum düzeyde yararlanılmaktadır.

Sistemde verimin arttırlıması için optimzer kullanılmıştır. Optimizer DC/DC dönüştürücü elektronik bir devredir. Optimizer sistemde, gölgelenme kaynaklı etkilerin minimize edilmesi, paneller arası uyumsuzluk (mismatch) farkından kaynaklı etkinin ortadan kaldırılması, farklı eğimde, yönelimde ve güçte panel kullanılmasına olanak sağlanması, yüksek DC voltajdan koruma sağlanması, panel bazlı izleme yapılabilmesi ve buna bağlı işlteme ve bakım maliyetlerinin düşürülmesi gibi faydalar sağlamaktadır. Ancak elektronik bir devre olduğundan çok düşükte olsa sistemde bir enerji kaybına neden olmakta(\%0,5) ve ayrıca güneş enerji sistemlerinde kullanılan ekstra bir cihaz olduğundan sistem maliyetinin yaklaşık \%7'sini oluşturarak sistemin ilk yatırım maliyetini yükseltmektedir.

Hidayet Türkoğlu Spor Kompleksi çatı alanı yaklaşık $1.500 \mathrm{~m}^{2}$ dir. Mevcut çatı alanına kurulu $169 \mathrm{kWp}$ doğu-batı yönelimi optimizerli fotovoltaik sistem yerine $30^{\circ}$ güney yönelimli güneş enerji sistemi tesis edilseydi, $110,5 \mathrm{kWp}$ kurulu güçte bir sistem kurulabilecekti. Mevcut çatı alanı için güney yönelimli sistem yerine doğu-batı yönelimli sistem tesis edilerek kurulu güçte yaklaşık $\% 35$ 'lik bir artış sağlanarak $58,5 \mathrm{kWp}$ daha fazla kurulum yapılmıştır.

Aynı güçler yani 169 kWp'lık kurulumlar için yönelimden kaynaklı farkı görmek adına her iki sistem simüle edilmiştir. Aynı güçte farklı yönelimlerde yapılan simülasyon sonuçlarına göre doğu-batı yönelimli sistem $192.829 \mathrm{kWh}$, güney yönelimli sistemin ise $211.250 \mathrm{kWh}$ üretim yaptığı görülmüş̧ür. Aynı güçlerde doğu-batı yönelimli sistemin güney yönelimli sisteme göre $\% 9,5$ daha az üretim yaptığı görülmüştür.

Mevuct çatı alanına kurulabilecek $169 \mathrm{kWp}$ doğu-batı yönelimi optimizerli fotovoltaik sistem ile $110,5 \mathrm{kWp}$ güney yönelimli fotovoltaik sistemin simülasyon sonuçları incelendiğinde doğu-batı yönelimli sistemin 192,88 MWh, güney yönelimli sistemin ise 
137,63 MWh elektrik üretimi yaptığı görülmüştür. Simüle edilen farklı güç ve yönelimdeki sistemlerin, enerji üretim değerleri kıyaslandığında; $169 \mathrm{kWp}$ doğu-batı yönelimli güneş enerji sisteminin, 110,5 kWp güney yönelimli güneş enerji sistemine göre yıllık (192.829 - 137.633) / 137.633=\% 40 daha fazla üretim yaptığı görülmektedir. Aynı çatı alanına güney yönelimli kurulum yerine doğu-batı yönelimli güneş enerji sistemi kurarak güneş enerjisinden \%40 daha fazla yararlanılabilmektedir.

$169 \mathrm{kWp}$ doğu-batı yönelimi optimizerli fotovoltaik sistem, veri kayıt ve uzaktan izleme sisteminden alınan gerçek zamanlı verilere göre ise 202.85 MWh elektrik üretimi gerçekleştirilmiştir.169 kWp gücündeki doğu-batı yönelimli sistemin gerçek zamanlı enerji üretim değerleri ve $110,5 \mathrm{kWp}$ güney yönelimli güneş enerji sisteminin PVSol simülasyonu sonucu bulunan enerji üretim değerleri ile üretim getirisi, engellenen karbon $\left(\mathrm{CO}_{2}\right)$ salınımı, doğaya sağlanan ağaç katkısı, elektrik tüketimi karşılanacak hane sayısı gibi veriler bulunmuştur. Söz konusu üretimler kıyaslandığında $169 \mathrm{kWp}$ kurulu güce sahip güney yönelimli sistem $110,5 \mathrm{kWp}$ kurulu güçteki güney yönelimli güneş enerji sistemine göre y1lda $(202.846-137.633)=65.213 \mathrm{kWh}$ daha fazla elektrik üretmiştir. Bu üretimle yılda \%47 oranında daha fazla elektrik üretimi gerçekleştirerek 53.607 TL daha fazla getiri sağlanmıştır. Ayrıca 33,91 ton daha fazla karbon salınımını engellenerek doğaya 864 adet ağaç dikimine eşdeğer katkı sağlanmıştır. Bununla birlikte 42 adet daha fazla hanenin elektrik tüketimini karşılamaktadır [15].

2020 yılına göre $169 \mathrm{kWp}$ kurulu güce sahip güney yönelimli bir güneş enerji sisteminin maliyeti 750.000 TL+ KDV olurken aynı çatı alanına kurulabilecek 110,5 kWp kurulu güçteki güney yönelimli güneş enerji sisteminin maliyeti ise 515.000 TL+ KDV olmaktadır. İlk yatırım aşamasında $169 \mathrm{kWp}$ kurulu güçteki güney yönelimli güneş enerji sistemi $235.000 \mathrm{TL}+\mathrm{KDV}$ yani \% 45 daha yüksek maliyetli olmaktadır. Söz konusu maliyetler, modül enerji düşüş profili ve güncel elektrik birim fiyatı baz alınarak yapılan maliyet analizine göre $169 \mathrm{kWp}$ kurulu güce sahip güney yönelimli bir güneş enerji sisteminin yatırım geri dönüş süresi 6,7 yıl olurken $110,5 \mathrm{kWp}$ kurulu güçteki güney yönelimli bir güneş enerji sisteminin yatırım geri dönüş süresi 6,5 yıl olmaktadır. Yatırım geri dönüş süresi olarak söz konusu iki sistem karşılaştırıldığında 110,5 kWp kurulu güçteki güney yönelimli güneş enerji sisteminin yatırım geri dönüş 0,2 yıl daha erken olmaktadır.

Güneş enerji sistemlerinde teknolojinin hızla gelişmesiyle birlikte her geçen gün dünya genelinde üretim maliyetleri düşmekte, güneş paneli verimleri ise artmaktadır. Ayrıca ülkemizde son yıllarda elektrik birim fiyatında ciddi artışlar görülmektedir. Güneş enerji sistemlerinde maliyetlerin her geçen gün düşmesi ve elektrik birim fiyatındaki artışlar ile yatırım geri dönüş süreleri azalmaktadır. Nitekim güneş enerji sisteminin kurulumuna başlandığı 2016 yılına göre yapılan hesaplamalarda yatırım geri dönüş süresi 15,7 yıl olarak bulunmuştu. Ancak güncel sistem maliyeti ve güncel elektrik birim fiyatı baz alınarak yapılan maliyet analizine göre $169 \mathrm{kWp}$ doğu-batı yönelimli güneş enerji santralinin yatırım geri dönüş süresi 6,7 yıl olarak bulunmuştur.

Bu çıktılar doğrultusunda doğu-batı yönelimli güneş enerji sisteminin avantaj ve dezavantajları aşağıda verilmiştir.

- Aynı birim alanda \%35 daha fazla kurulu güçte kurulum yapılmaktadır.

- Simülasyona göre ilk yıl için \%40 daha fazla elektrik üretimi yapılmaktadır.

- Gelişen teknolojiyle birlikte sistem maliyetleri düş̧ügünnde veya elektrik birim fiyatları yükseldiğinde, yatırım geri dönüş süreleri aynı alandaki güney yönelimli kuruluma göre daha kısa süreli olacaktır.

- Güneşlenme süresinin yüksek olduğu yaz aylarında aynı güçteki güney yönelimli kurulumdan daha fazla enerji üretmektedir.

- Aynı güçlerde doğu-batı yönelimli sistemin güney yönelimli sisteme göre \%9,5 daha az üretim yaptı̆ğ görülmüştür.

- İlk yatırım maliyetleri yüksektir.

- Yatırım geri dönüşs süresi daha uzundur.

Doğu-batı yönelimli güneş enerji sistemlerinin, güneşlenme süresinin yüksek olduğu ekvatora yakın olan bölgelerde kurulması önerilmektedir. Ülkemizde ise güney bölgelerde önerilmekte olup kuzey kısımlar için elektrik birim fiyatları yükseldikçe ve/veya kurulum maliyetleri düştükçe daha uygun hale gelecektir.

\section{Kaynakça}

[1] Bedeloğlu, A. (2010). Fotovoltaik Teknolojisi: Türkiye ve Dünyadaki Durumu, Genel Uygulama Alanları ve Fotovoltaik Tekstiller. [Electronic Version] Electronic Journal of Textile Technologies. 4: 43-58. (12 Mart 2019).

[2] İnternet: https://www.iea.org/topics/renewables/solar/ Son Erişim Tarihi: 02.01.2020.

[3] TEİAŞ. (2018). Faaliyet Raporu. https://www.teias.gov.tr/tr-TR/sektor-raporlari

[4] TEİAŞ. (2018). Türkiye Elektrik Enerjisi 5 Yıllık Üretim Kapasite Projeksiyonu (2018-2022). https://www.teias.gov.tr/sites/default/files/2018-09/Kapasite_Projeksiyonu_2018_2022.pdf

[5] Ataş, H. (2018). Türkiye İçin Birincil Enerji Kaynaklarının Büyüme Üzerine Etkileri, Yüksek Lisans Tezi, Çukurova Üniversitesi Sosyal Bilimler Enstitüsü, Adana. 2,9-11.

[6] EPDK. (2019). Elektrik Piyasası Aylık Sektör Raporları. https://www.epdk.org.tr/Detay/Icerik/3-0-23-3/elektrikaylik-sektorraporlar (1 Kasim 2019).

[7] Enerji İşleri Genel Müdürlüğü. (2019). Güneş Enerjisi Potansiyel Atlası. http://www.yegm.gov.tr/MyCalculator/Default.aspx (1 Nisan 2019).

[8] Sankar, A. ve Kalathil, A. (6-9 August 2014). Qualitative Validation Of Empirically Observed Higher Generation In East-West Orientated PV Arrays Over Conventional South Orientation. Region 10 Humanitarian Technology Conference. India: 25-28.

[9] İnternet: https://www.valksolarsystems.com/en/systems/flat-roofs/portrait/south/valkpro-p10-south Son Erişim Tarihi: 05.01.2020. 
[10] İnternet: https://www.valksolarsystems.com/en/systems/flat-roofs/landscape/east-west/valkpro-110-east-west Son Erişim Tarihi: 05.01.2020.

[11]Solar Edge. (2019). Güç Optmizeri https://www.solaredge.com/sites/default/files/se-homeowners-brochure-tur.pdf (24 Aralık 2019).

[12] Varış, Ç. (2017). Çift Eksenli Güneş Takip Sisteminin Pilot Uygulaması, Üretim Değerlendirmesi Ve Ekonomik Analizi, Yayınlanmamış Yüksek Lisans Tezi. İstanbul: Yıldız Teknik Üniversitesi FBE.

[13]Solar Edge. (2019). Solar Edge İleme Sistemi. https://monitoring.solaredge.com/solaredge-web/p/home (24 Aralık 2019).

[14]SSRN. (2019). Feasibility Study Of City Scale Solar Power Plants Using Public Buildings.https://papers.ssrn.com/sol3/papers.cfm?abstract id=3397772 (17 June 2019).

[15]Environmental Protection Agency. (2015). Karbon Hesabl. https://www.epa.gov/energy/greenhouse-gases-equivalenciescalculator-calculations-and-references (6 Temmuz 2019). 